\title{
Tumor Characteristics and Treatment Outcomes of Older Women with Breast Cancer in Jordan
}

Hikmat Abdel-Razeq ( $\nabla$ habdelrazeq@khcc.jo )

King Hussein Cancer Center https://orcid.org/0000-0003-2833-6051

\section{Fadwa Abdel Rahman}

King Hussein Cancer Center

Hanan Al-Masri

King Hussein Cancer Center

Hazem Abdulelah

King Hussein Cancer Center

Mahmoud Abu Nasser

King Hussein Cancer Center

Mourad Salam

King Hussein Cancer Center

Ayat Taqash

King Hussein Cancer Center

\section{Research article}

Keywords: Breast cancer; Older women; Jordan; Comorbidities

Posted Date: December 20th, 2019

DOI: https://doi.org/10.21203/rs.2.16951/v2

License: (c) (1) This work is licensed under a Creative Commons Attribution 4.0 International License.

Read Full License 


\section{Abstract}

Background : Less than $10 \%$ of newly diagnosed breast cancer in our region are diagnosed in women 70 years or older. Treatment plans of such patients is less clear and have poor outcomes. In this paper, we describe clinical presentation, tumor characteristics and treatment outcomes in such patients. Methods : Consecutive patients aged 65 years or older with pathologically-confirmed diagnosis of breast cancer were included. Medical records and hospital databases were searched for patients' characteristics and treatment outcomes. Results : A total of 553 patients, median age 70 (range: 65-91) years, were included. On presentation, 114 (20.6\%) patients had metastatic disease and was mostly visceral (81; $71.1 \%)$. Patients with non-metastatic disease had poor pathological features including node-positive in 244 (55.6\%), GIII in 170 (38.7\%) and lymphovascular invasion in 173 (39.4\%). Patients were treated less aggressively; 144 (32.8\%) patients with early-stage disease and 98 (86.0\%) with metastatic disease never had chemotherapy. After a median follow up of 45 months, 5-year overall survival for the whole group was $67.6 \%$. Survival was better for patients with non-metastatic disease $(78.8 \%$ vs. $25.4 \%, P<0.001)$ and for those with node-negative compared to node-positive disease $(85.4 \%$ vs. $74.1 \%, P=0.002)$. On Cox regression, only positive lymph nodes were associated with poor outcome in patients with non-metastatic disease (Hazard Ratio [HR], 1.75; 95\% Cl: 1.006-3.034, $\mathrm{P}=0.048$ ). Conclusions : Older Jordanian women with breast cancer present with more aggressive features and advanced-stage disease that reflect poorly on treatment outcomes. Because of comorbidities and poor performance status, some patients were not aggressively treated.

\section{Background}

Accounting for almost $40 \%$ of all cancer cases, breast cancer is the most common cancer in Jordan and its incidence increases with age. ${ }^{1}$ Less than $10 \%$ of newly diagnosed breast cancer in the region, compared to $30 \%$ in western societies, are diagnosed in women 70 years or older. ${ }^{2}$ Such group of patients remains underrepresented in clinical trials ${ }^{3}$, their treatment plan is less clear and have poor outcomes. ${ }^{4,5}$

Pathological features and clinical presentation among older patients with breast cancer are not the same as younger ones. With aging, the percentage of HER-2 positive disease decreases while ER and PRpositivity increases. ${ }^{6}$ Such features, though implicate a better prognosis, are not reflected in real clinical outcomes.

Many previously published studies have shown that older patients are more likely to receive nonstandardized care and usually depends more on physician's preference. ${ }^{7-11}$ Compliance to planned treatment is always an issue with increasing age. ${ }^{12}$

The poor outcome observed among older patients can also be attributed to comorbidities and its associated medications. Such comorbidities have the potential to affect the mortality of such older women regardless of their breast cancer or its treatment. ${ }^{13}$ Women with early-stage breast cancer and comorbid conditions, are likely to die from causes other than breast cancer. In one study, using 
Surveillance, Epidemiology, and End Results (SEER)-Medicare database, inpatient, outpatient, and physician visits were searched to determine the presence of 13 comorbid conditions present at the time of diagnosis. A total of 64,034 patients with breast cancer diagnosed at a median age of 75 years were included. The 13 individual comorbid conditions were associated with decreased overall survival and increased mortality. ${ }^{14}$

To date, the consequences of treatment disparities, particularly the under treatment of the older patients, have been poorly assessed in population like ours. In this paper, we describe clinical presentations, tumor characteristics, treatment modalities and outcomes among older Jordanian patients with breast cancer.

\section{Methods}

Consecutive patients aged 65 years or older with a pathologically-confirmed diagnosis of breast cancer, treated and followed at our institution between 2006 and 2018 were included. Medical records and hospital databases were searched for patients' characteristics and treatment outcomes. Patients who lack appropriate follow up and all non-Jordanian patients were excluded. Data, including detailed pathological features, tumor stage, type of surgery, systemic chemotherapy, radiation therapy, tumor recurrence, and death, were collected through chart review. Data related to tumor size, histological type, lymph node status and the number of metastatic lymph nodes, were obtained directly from the pathology reports. All patients had a central pathology reviewed at our institution. Vital status and death dates were confirmed using our local cancer registry database and the national civil department database. Patients were treated on unified institutional clinical practice guidelines based on standard international ones. Treatment plan was approved by a regularly-conducted weekly multidisciplinary meeting. This research was reviewed and approved by our IRB committee.

\section{Statistical Analysis:}

Survival duration was calculated from the date of diagnosis until the date of death or last clinical followup; the median follow-up was 45 (range: 0.23-154) months. The survival rates were calculated using the life table methods and presented using the Kaplan-Meier method. For statistical comparison, overall survival (OS) curves were obtained at 5 years. In addition, multivariate analysis was done for the significant factor by using Cox proportional hazards regression model. A significance criterion of $p \leq$ 0.05 was used in the analysis. All analyses were performed using SAS version 9.4 (SAS Institute Inc, Cary, NC).

\section{Results}

A total of 553 patients were included; 12 (2.2\%) were males. Median age was 69 (range: 65-91) years. However, only $121(21.9 \%)$ were 75 years or older and $40(7.2 \%)$ were $\geq 80$ years old. Family history of breast cancer in first degree relatives was identified among $115(20.8 \%) ; 18(15.7 \%)$ of them with an additional cancer other than breast. Invasive ductal carcinoma (IDC) was the predominant pathology 
identified among 460 (83.2\%) while invasive lobular carcinoma (ILC) was seen among 60 (10.8\%). On presentation, 114 (20.6\%) patients had metastatic disease and was mostly visceral $(81 ; 71.1 \%)$. Patients with non-metastatic disease had poor pathological features including node-positive in 244 (55.6\%), G-III in $170(38.7 \%)$ and lymphovascular invasion in 173 (39.4\%). Among the 501 patients with known HER-2 status, $92(18.4 \%)$ were positive and $38(7.6 \%)$ had triple-negative disease. Larger tumors with T3 and T4 disease were seen among a total of $61(13.9 \%)$ patients, Table-1.

Among the patients with non-metastatic disease, modified radical mastectomy was the most performed surgery $(274 ; 62.4 \%)$ while 125 (28.5\%) patients had breast conserving surgery (BCS). Additionally, 29 $(6.6 \%)$ never had surgery mostly because of patients' refusal $(n=5)$, comorbidities or poor performance status $(n=20)$. Sentinel lymph node biopsy ( $(\mathrm{sLN})$ was performed on $156(38.0 \%)$ while axillary dissection; upfront or following a positive sLN, was performed on 285 (69.5\%). Breast reconstruction, both immediate and delayed, was performed on only 20 (4.9\%) of the patients, Figure-1.

Among patients with non-metastatic disease, 279 (63.6\%) were treated with chemotherapy; 67 (24.0\%) were in the neoadjuvant setting. However, 144 (32.8\%) had no chemotherapy because of low-risk disease, patient refusal or poor performance status. Similarly, chemotherapy was offered for only $16(14.0 \%)$ patients with metastatic disease. All patients, with hormone-receptor positive tumors, were treated with aromatase inhibitors.

After a median follow up of 45 (range: $0.23-154$ ) months, 5-year overall survival for the whole group was $67.6 \%$ while the median overall survival was 104.2 months. Survival was significantly better for patients with non-metastatic disease with 5 -year OS of $78.8 \%$ compared to $25.4 \%$ for patients with metastatic disease; $P<0.0001$ (Figure-2).

Among the patients with non-metastatic disease, survival was significantly better for patients with nodenegative compared to those with node-positive disease; 5 -year OS was $85.4 \%$ and $74.1 \%$, respectively, $\mathrm{P}=0.002$ (Figure-3a). Survival advantage was also noted among patients with no lymphovascular invasion (LVI) and those with low-grade disease as illustrated in Figure-3b and Figure-3c, respectively.

On Cox regression, only positive lymph nodes were associated with poor outcome in patients with nonmetastatic disease (Hazard Ratio [HR], 1.75; 95\% Cl: 1.006-3.034, $\mathrm{P}=0.048$ ). Tumor grade (grade-III versus grade I and II) and LVI were not significant, Table-2.

\section{Discussion}

Jordan is a middle-income country with an estimated total population of 10 million, the majority of them are the younger generation, and only $3.7 \%$ are 65 years or older. ${ }^{15}$ However, given the changing demographics and health care, this group is expanding rapidly.

Age is an important risk factor for breast cancer. However, data on whether patients' age at diagnosis is also related to breast cancer treatment outcomes and survival in our region is lacking. Life expectancy for 
Jordanian females is significantly lower compared to western societies. ${ }^{16}$

Our data presented in this paper shows that a significant proportion of our patients, especially those with metastatic disease, were not treated aggressively with chemotherapy or surgery. Less than two-thirds of those with non-metastatic disease and only $14 \%$ of those with the metastatic disease received chemotherapy. Similarly, surgical interventions were less aggressive, too. Less than a third had BCS while sentinel LN biopsy was performed on $38.0 \%$ and axillary dissection was performed less often than younger patients. ${ }^{17}$ Though breast reconstructive surgery is not commonly performed in our region, less than $5 \%$ of our older patients included in this study had it.

Avoidance of both surgery and chemotherapy in this age group was also reported in western literature. ${ }^{18}$ In one study, hormonal therapy uses as the sole therapy for breast cancer at UK hospitals increased from $2.8 \%$ in patients aged $65-69$ years to $40.3 \%$ among patients aged 70 years or older. ${ }^{19}$ Furthermore, it has been shown in previous studies that older women are less likely to receive adjuvant radiotherapy. ${ }^{20-22}$

Variation in the rate of surgery for breast cancer persists even in the same hospital. In one study that utilized data on over 17000 women aged 70 years or more with ER-positive operable breast cancer from two UK regional cancer registries demonstrated considerable variation in rates of surgery. Despite adjusting for case-mix, this variation persisted at the hospital level. ${ }^{23}$ Utilizing the Charlson's Index of comorbidity, Giordano and colleagues reported that among women aged 75 years or older treated for breast cancer with clinical stage I-IIla, the odds of having surgery in accordance with the guidelines were 0.32 (95\% confidence interval $(\mathrm{Cl}) 0.20$ to 0.51 ) times lower than those of $55-64$-year-olds. ${ }^{24}$

Because treatment decisions for such older patients are based mostly on age rather than health status or potential benefit, objective tools that assess the fitness and functional status of older patients for the planned cancer treatment is highly needed. ${ }^{25,26} \mathrm{~A}$ study from Sweden that included 4,453 women diagnosed with breast cancer in Malmö University Hospital between 1961 and 1991 looked at the effect of age on breast cancer-specific mortality. When adjusted for potential confounders, including stage at diagnosis, age was a significant factor only for patients aged 80 years or more. ${ }^{27}$

Based on women diagnosed with breast cancer between 2008 and 2014, the 5-year OS rate, published by the American Cancer Society, based on SEER (Surveillance, Epidemiology, and End Results)-database, for patients with stage IV disease is $27 \% .{ }^{28}$ This number had increased from $22 \%$ in $2012 .{ }^{29}$ The SEER database, however, does not group cancers by AJCC TNM stages, instead, it groups cancers into localized, regional, and distant stages. The 5 -year OS rates for patients with regional disease is $85 \%$. Our survival rates are a little lower. However, the two populations are not comparable. Several of the known poor prognostic pathological features, like positive axillary lymph nodes and high-grade tumors are more prevalent in our patient population compared to what was reported in western literature. The prevalence of comorbidities among our population, in general, is high enough to explain our lower life expectancy and this obviously affect the aggressiveness of anticancer therapy for this population and may be another factor to explain this difference in OS. 
Our study is not without limitations. This is a retrospective study with limited data on potentially important factors like performance status, detailed comorbidities, and social support. Though our study is a single-institution one, our center treats over two-thirds of all breast cancer patients in the country.

\section{Conclusions}

Due to late presentation, older women with breast cancer in developing countries present with more aggressive features and advanced-stage disease that reflect poorly on treatment outcomes. Because of comorbidities and poor performance status, some patients are not aggressively treated. Future regional studies should focus on identifying tumor and patient-related characteristics and link it to objective measures that can be used to help target anti-cancer therapy for older patients most likely to benefit. Awareness about the need to treat "older patients" more aggressively is growing and plans to create geriatric oncology service are ongoing.

\section{Abbreviations}

HR: Hazard Ratio

HER2: Human Epidermal growth factor Receptor 2

ER: Estrogen Receptor

PR: Progesterone Receptor

SEER: Surveillance Epidemiology and End Results

IRB: Institutional Review Board

OS: Overall Survival

BCS: Breast Conserving Surgery

sLN: Sentinel lymph node

LVl: Lymphovascular Invasion

\section{Declarations}

Ethics approval and consent to participate: The study was approved by our Institutional Review Board (IRB). All patients signed informed consent.

Consent for publication: Data submitted are entirely unidentifiable and there are no details on individuals reported within the manuscript. 
Availability of data and material: Data will be made available as per the Journal and publisher rules and regulations.

\section{Competing interests: None}

\section{Funding: None}

Authors' contributions: First author HA conceived the research idea, planned it, supervised data collection, and took the lead in writing the manuscript. Second author FA participated in data collection. Third author HM participated in data collection and analysis. Fourth author HA participated in data collection and analysis. Fifth author MA participated in data collection and analysis. Sixth author MS participated in data collection and data analysis. Seventh author AT participated in data analysis. All authors have read and approved the manuscript.

Acknowledgements: The authors would like to thank Rayan Bater for her help in this research.

\section{Authors' information (optional)}

\section{References}

1. Ministry of Health 2014 Report. Available at: http://www.moh.gov.jo/Echobusv3.0/SystemAssets/2d0cc71d-d935-4d6f-a72c-73d60cd0a16c.pdf. Accessed on 29 July 2019. 2. GBD 2015 Eastern Mediterranean Region Cancer Collaborators. Burden of cancer in the Eastern Mediterranean Region, 2005-2015: findings from the Global Burden of Disease 2015 Study. Int J Public Health. 2018; 63(Suppl 1):151-164. 3. Hutchins LF, Unger JM, Crowley JJ, et al: Underrepresentation of patients 65 years of age or older in cancer-treatment trials. N Engl J Med 341:2061-2067, 1999 4. Gajdos C, Tartter PI, Bleiweiss IJ, et al: The consequence of undertreating breast cancer in the elderly. J Am Coll Surg 192:698-707, 2001 5. Giordano SH, Duan Z, Kuo YF, et al: Use and outcomes of adjuvant chemotherapy in older women with breast cancer. J Clin Oncol 24:2750-2756, 2006 6. Anderson W, Katki H, Rosenberg P. Incidence of breast cancer in the United States: current and future trends. J Natl Cancer Inst. 2011; 103:1397-402. 7. Bouchardy C, Rapiti E, Fioretta G, et al. Under treatment strongly decreases prognosis of breast cancer in elderly women. J Clin Oncol. 2003; 21:3580-7. 8. Schonberg M, Marcantonio E, Li D, et al. Breast cancer among the oldest old: tumor characteristics, treatment choices, and survival. J Clin Oncol. 2010; 28:2038-45. 9. YancikR, Wesley MN, Ries LA, et al. Effect of age and comorbidity in postmenopausal breast cancer patients aged 55 years and older. JAMA. 2001; 285(7):885-92. 10. Morgan J, Richards P, Francis M, et al. Case mix analysis and variation in rates of non-surgical treatment of older women with operable breast cancer. Br J Surg. 2015; 102(9):1056-63. 11. Lavelle K, Moran A, Howell A, et al. Older women with operable breast cancer are less likely to have surgery. Br J Surg. 2007;94: 1209-15 12. Kiderlen M, Ponti A, Mariano T, et al. Variations in compliance to quality indicators by age for 41,871 breast cancer patients across Europe: a European society of breast cancer specialists database analysis. Eur J Cancer. 2015; 51:1221-30. 13. Danese M, O’Malley C, Lindquist K, et al. An observational study of the prevalence and incidence of comorbid conditions in older 
women with breast cancer. Ann Oncol. 2012;23(7):1756-65 14. Patnaik JL1, Byers T, Diguiseppi C, Denberg TD, Dabelea D. The influence of comorbidities on overall survival among older women diagnosed with breast cancer. J Natl Cancer Inst. 2011;103(14):1101-11. 15. Department of Statistics, data available at: http://dosweb.dos.gov.jo/databank/Yearbook2017/YearBook2017.pdf. Accessed 24 June 2019 16. The World Bank country classification. Available at:

http://data.worldbank.org/country/jordan?view=chart. Accessed 09 May, 2019. 17. Abdel-Razeq H, Almasri H, Abdel Rahman F, et al. Clinicopathological characteristics and treatment outcomes of breast cancer among adolescents and young adults in a developing country. Cancer Manag Res. 2019; 11:98919897. 18. Bates T, Evans T, Lagord C, Monypenny I, Kearins O, Lawrence G. A population-based study of variations in operation rates for breast cancer, of comorbidity and prognosis at diagnosis: failure to operate for early breast cancer in older women. Eur J Surg Oncol. 2014 Oct; 40(10):1230-6. 19. Wyld L, Garg DK, Kumar ID, Brown H, Reed MWR. Stage and treatment variation with age in postmenopausal women with breast cancer: compliance with guidelines. Br J Cancer 2004; 90: 1486-1491. 20. Diab SG, Elledge RM, Clark GM. Tumor characteristics and clinical outcome of elderly women with breast cancer. J Natl Cancer Inst. 2000; 92(7):550-6. 21. Hancke K, Denkinger MD, Konig J, et al. Standard treatment of female patients with breast cancer decreases substantially for women aged 70 years and older: a German clinical cohort study. Ann Oncol. 2009;21(4):748-53 22. Gajdos C, Tartter PI, Bleiweiss IJ, Lopchinsky RA, Bernstein JL. The consequence of undertreating breast cancer in the elderly. J Am Coll Surg. 2001; 192(6):698-707. 23. Morgan J, Richards P, Francis M, et al. Case mix analysis and variation in rates of non-surgical treatment of older women with operable breast cancer. Br J Surg. 2015; 102(9):1056-63. 24. Giordano SH, Hortobagyi GN, Kau SWC, Theriault RL, Bondy ML. Breast cancer treatment guidelines in older women. J Clin Oncol 2005; 23: 783-791. 25. Audisio RA, Ramesh H, LongoWE, Zbar AP, Pope D. Preoperative assessment of surgical risk in oncogeriatric patients. Oncologist 2005; 10: 262-268. 26. Balducci L, Extermann M. Management of cancer in the older person: a practical approach. Oncologist 2000; 5:224-237. 27. Brandt J, Garne JP, Tengrup I, Manjer J. Age at diagnosis in relation to survival following breast cancer: a cohort study. World J Surg Oncol. 2015; 13:33. 28. Survival Rates for Breast Cancer. Available at: https://www.cancer.org/cancer/breast-cancer/understanding-abreast-cancer-diagnosis/breast-cancer-survival-rates.html. Accessed on 29 July, 2019 29. Breast Cancer Survival Rates for all types of breast cancers. Available at https://breast-cancer.ca/survicanc/. Accessed on 29 July 2019.

\section{Tables}

Table-1: Patients characteristics, $(n=553)$ 


\begin{tabular}{|c|c|c|c|}
\hline \multicolumn{2}{|l|}{ Characteristics } & Number of patients & Percentage \\
\hline Gender & $\begin{array}{c}\text { Female } \\
\text { Male }\end{array}$ & $\begin{array}{l}541 \\
12\end{array}$ & $\begin{array}{l}97.8 \% \\
2.2 \%\end{array}$ \\
\hline Age group (years) & $\begin{array}{c}65-69 \\
70-74 \\
75-79 \\
\geq 80\end{array}$ & $\begin{array}{l}270 \\
162 \\
81 \\
40\end{array}$ & $\begin{array}{l}48.8 \% \\
29.3 \% \\
14.6 \% \\
7.2 \%\end{array}$ \\
\hline Histology & $\begin{array}{c}\text { IDC } \\
\text { ILC } \\
\text { Others }\end{array}$ & $\begin{array}{l}460 \\
60 \\
33\end{array}$ & $\begin{array}{l}83.2 \% \\
10.8 \% \\
6.0 \%\end{array}$ \\
\hline Tumor Size $(\mathrm{T}) *$ & $\begin{array}{l}\text { Tis } \\
\mathrm{T} 1 \\
\mathrm{~T} 2 \\
\mathrm{~T} 3 \\
\mathrm{~T} 4 \\
\mathrm{Tx}\end{array}$ & $\begin{array}{l}2 \\
114 \\
229 \\
48 \\
13 \\
35\end{array}$ & $\begin{array}{l}0.23 \% \\
26.0 \% \\
52.2 \% \\
10.9 \% \\
3.0 \% \\
7.5 \%\end{array}$ \\
\hline Axillary nodal metastasis* & $\begin{array}{c}\text { Negative } \\
\text { Positive } \\
\text { Unknown }\end{array}$ & $\begin{array}{l}178 \\
244 \\
17 \\
\end{array}$ & $\begin{array}{l}40.5 \% \\
55.6 \% \\
3.9 \% \\
\end{array}$ \\
\hline Stage & $\begin{array}{c}\text { I } \\
\text { II } \\
\text { III } \\
\text { IV } \\
\text { NA }\end{array}$ & $\begin{array}{l}74 \\
109 \\
241 \\
114 \\
15\end{array}$ & $\begin{array}{l}13.4 \% \\
19.7 \% \\
43.6 \% \\
20.6 \% \\
2.7 \%\end{array}$ \\
\hline Grade* & $\begin{array}{c}\text { I } \\
\text { II } \\
\text { III } \\
\text { NA } \\
\end{array}$ & $\begin{array}{l}38 \\
226 \\
170 \\
5 \\
\end{array}$ & $\begin{array}{l}8.7 \% \\
51.5 \% \\
38.7 \% \\
1.1 \% \\
\end{array}$ \\
\hline Lymphovascular invasion (LVI)* & $\begin{array}{c}\text { Negative } \\
\text { Positive } \\
\text { Unknown }\end{array}$ & $\begin{array}{l}204 \\
173 \\
62 \\
\end{array}$ & $\begin{array}{l}47.0 \% \\
39.4 \% \\
14.1 \% \\
\end{array}$ \\
\hline Progesterone Receptors (PR) & $\begin{array}{l}\text { Negative } \\
\text { Positive } \\
\text { Unknown }\end{array}$ & $\begin{array}{l}104 \\
441 \\
8\end{array}$ & $\begin{array}{l}18.8 \% \\
79.7 \% \\
1.4 \%\end{array}$ \\
\hline Estrogen Receptors (ER) & $\begin{array}{c}\text { Negative } \\
\text { Positive } \\
\text { Unknown }\end{array}$ & $\begin{array}{l}87 \\
458 \\
8\end{array}$ & $\begin{array}{l}15.7 \% \\
82.8 \% \\
1.4 \% \\
\end{array}$ \\
\hline HER2-neu^ & $\begin{array}{l}\text { Negative } \\
\text { Positive } \\
\text { Unknown }\end{array}$ & $\begin{array}{l}409 \\
92 \\
52\end{array}$ & $\begin{array}{l}81.6 \% \\
18.4 \% \\
9.4 \%\end{array}$ \\
\hline
\end{tabular}


NA: Not available; *For M0 patients $\mathrm{n}=439 ;$ ^ From the 501 patients tested for HER2

Table-2: Cox Regression for patients with non-metastatic disease

\begin{tabular}{|l|l|c|c|c|c|}
\hline \multicolumn{2}{|c|}{ Parameter } & $\begin{array}{c}\text { p- } \\
\text { value }\end{array}$ & $\begin{array}{c}\text { Hazard } \\
\text { Ratio }\end{array}$ & \multicolumn{2}{c|}{$\begin{array}{c}\text { 95\% Hazard Ratio } \\
\text { Confidence } \\
\text { Limits }\end{array}$} \\
\hline Nodal metastasis & $\begin{array}{l}\text { Positive vs. } \\
\text { Negative }\end{array}$ & 0.0476 & 1.75 & 1.006 & 3.034 \\
\hline Triple-Negative & Yes vs. No & 0.1901 & 1.70 & 0.770 & 3.735 \\
\hline Grade & III vs. I+II & 0.1595 & 1.41 & 0.874 & 2.264 \\
\hline $\begin{array}{l}\text { Lymphovascular invasion } \\
\text { (LVI) }\end{array}$ & $\begin{array}{l}\text { Positive vs. } \\
\text { Negative }\end{array}$ & 0.3123 & 1.30 & 0.783 & 2.153 \\
\hline
\end{tabular}

Figures

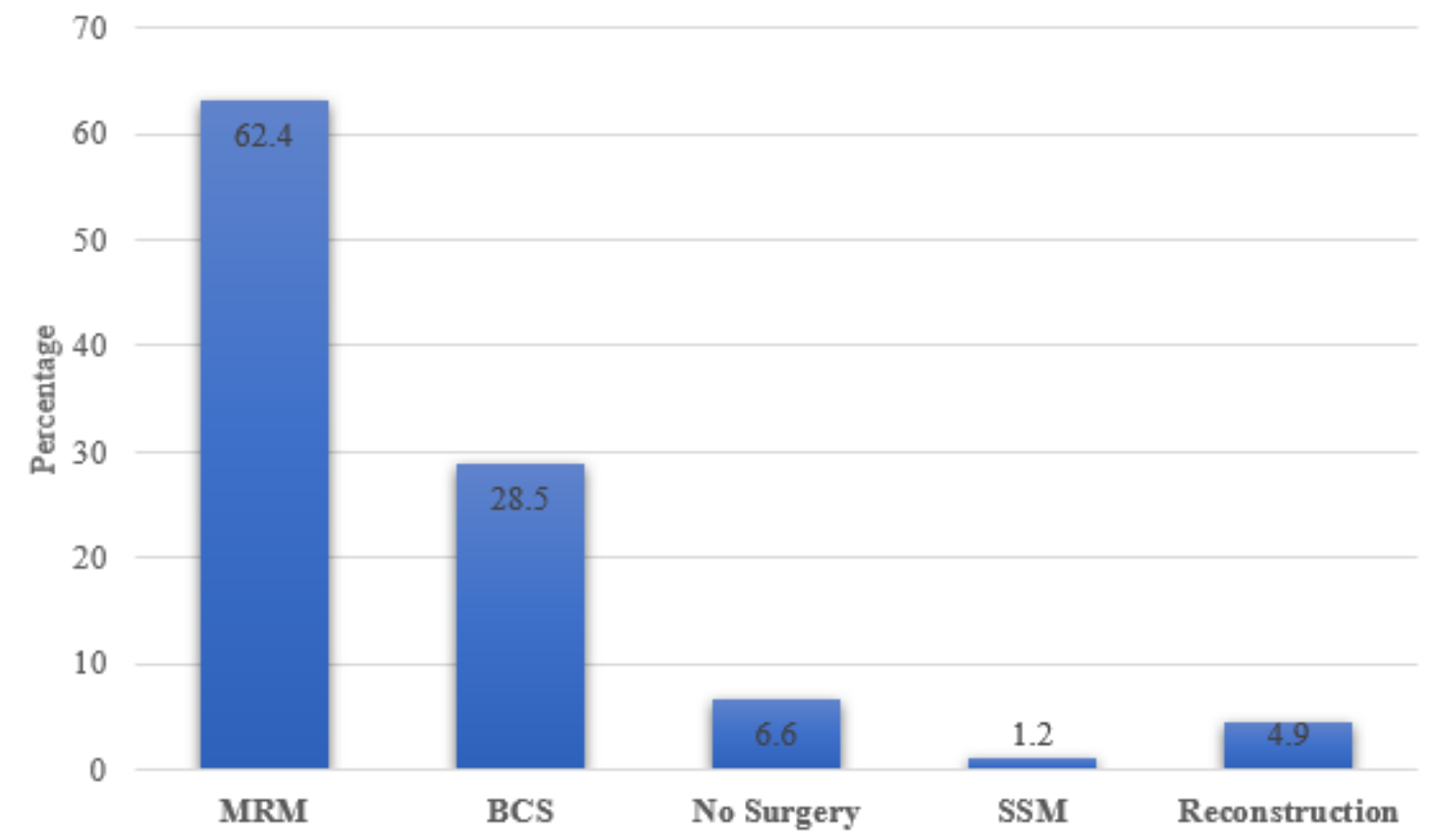

Figure 1

Surgical interventions for patients with non-metastatic disease (\%) 


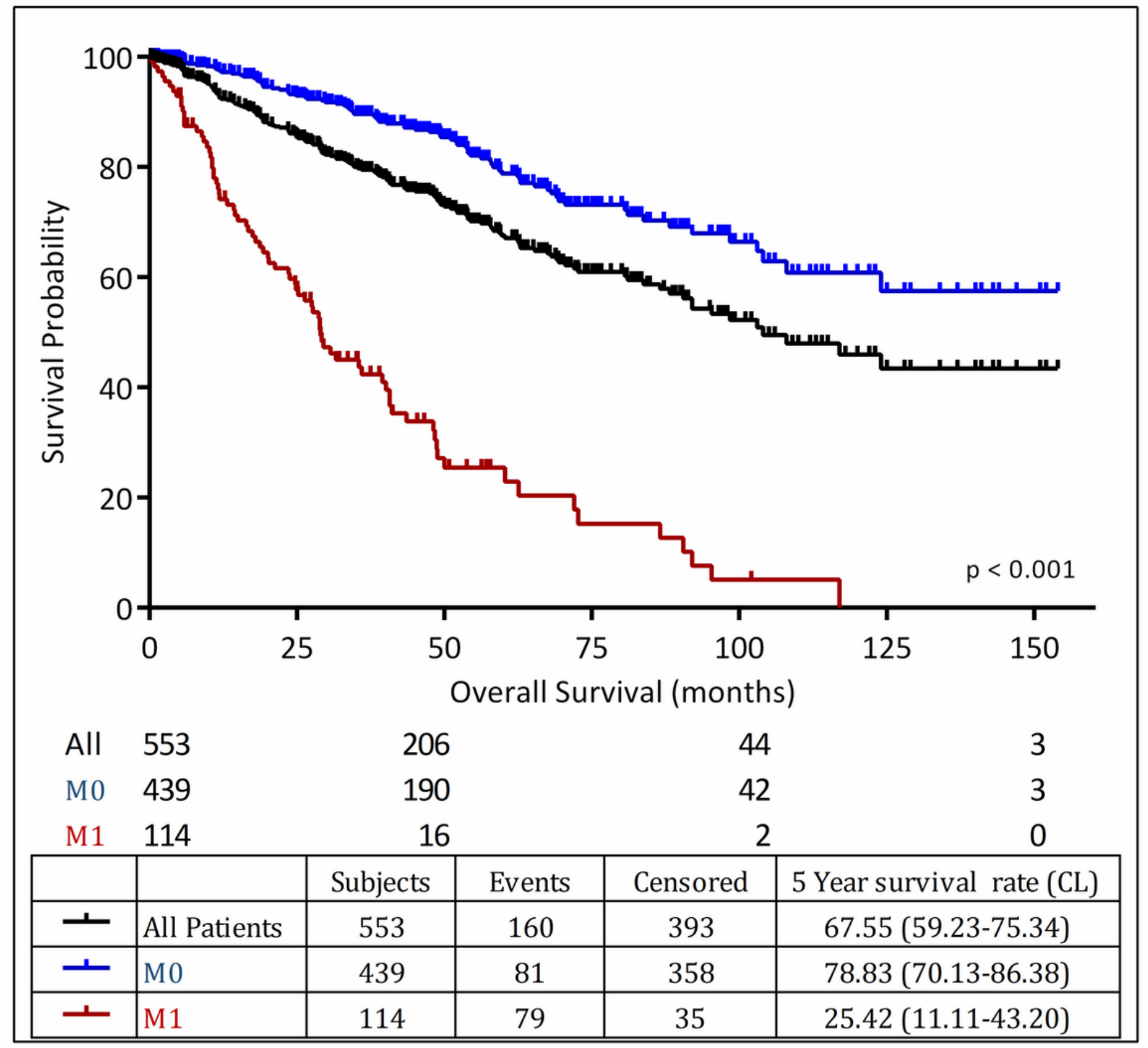

Figure 2

Overall survival for the whole group $(n=553)$ 

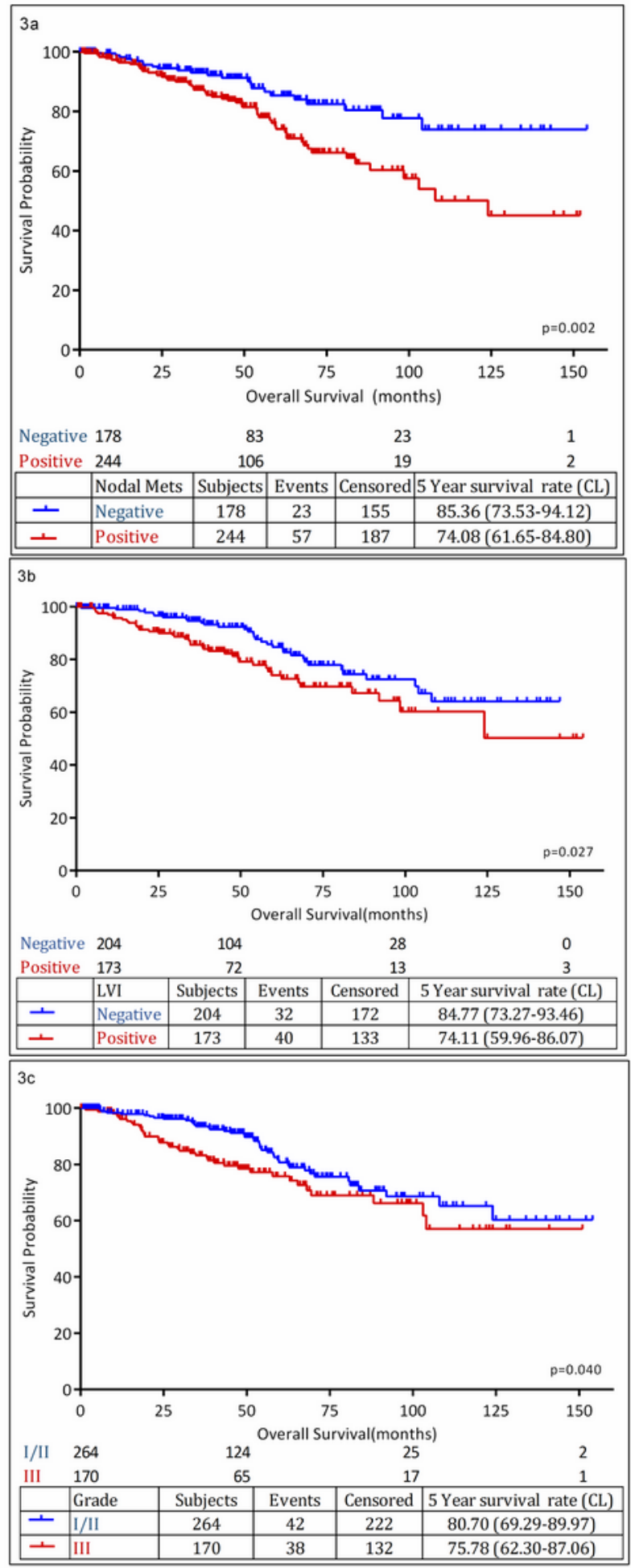

\section{Figure 3}

3a: Overall survival of Node-Positive versus Node-Negative.3b: Overall survival of Lymphovascular invasion. 3c: Overall survival of grade I/ II versus grade III:

\section{Supplementary Files}


This is a list of supplementary files associated with this preprint. Click to download.

- OverallsurvivalbyageERPRHER2.pdf 